\title{
UM PROTOCOLO PARA A ALOCAÇÃO DE RECURSOS E CONTROLE DE ACESSO EM REDES EM MALHA SEM FIO
}

Roni Francis Shigueta, Paulo Henrique Aguiar, Viviane Furtado, Luan Pablo Franco

Universidade Paranaense - UNIPAR, PR. e-mail: shigueta@yahoo.com

RESUMO - Este trabalho apresenta um protocolo para a alocação de recursos e controle de acesso em redes em malha sem fio. A alocação de recursos permite selecionar um canal de frequência diferente de modo a diminuir a interferência na transmissão de dados entre dispositivos vizinhos. Além de disso, permite a transmissão simultânea de dados, aumentando a vazão total da rede. O controle de acesso ao canal notifica aos dispositivos vizinhos em qual canal se deseja realizar a transmissão dos dados. Os experimentos são realizados em cenários de redes sem fio utilizando o simulador NS-3. Os resultados mostram que a utilização de dois canais apresentam valores próximos a utilização de um único canal, porém conforme o número de canais aumenta a vazão da rede também aumenta.

Palavras-chave: Redes em malha sem fio; alocação de recursos; controle de acesso.

\section{A PROTOCOL FOR RESOURCE ALLOCATION AND ACCESS CONTROL IN WIRELESS MESH NETWORKS}

ABSTRACT - This paper presents a protocol for resource allocation and access control in wireless mesh networks. Resource allocation allows select a different channel in order to reduce the interference in the transmission of data between neighboring devices. Moreover, the use of different channels allows multiple devices to transmit data simultaneously, increasing the total throughput in the network. The access control notifies neighbors which channel the communication will occur and control access to the channel. The experiments are performed on scenarios of wireless networks using NS-3 simulator. The results show that the use of two channels has similar values to the use a single channel, but according the number of channels increases, the network throughput also increases.

Recebido em: 11/10/2014 Keywords: Wireless mesh networks; resource allocation; access control. 


\section{INTRODUÇÃO}

Este artigo apresenta um protocolo para a alocação de recursos e controle de acesso em redes em malha sem fio. Uma rede em malha sem fio é uma rede no qual os roteadores são estáticos e permitem realizar o encaminhamento de pacotes entre origem e destino (ZHANG, 2007).

A Figura 1 ilustra um exemplo de uma rede em malha sem fio. Nesta rede, os pacotes do prédio1 são encaminhados para o prédio2, utilizando roteadores intermediários localizados nas antenas 1 e 2, respectivamente .

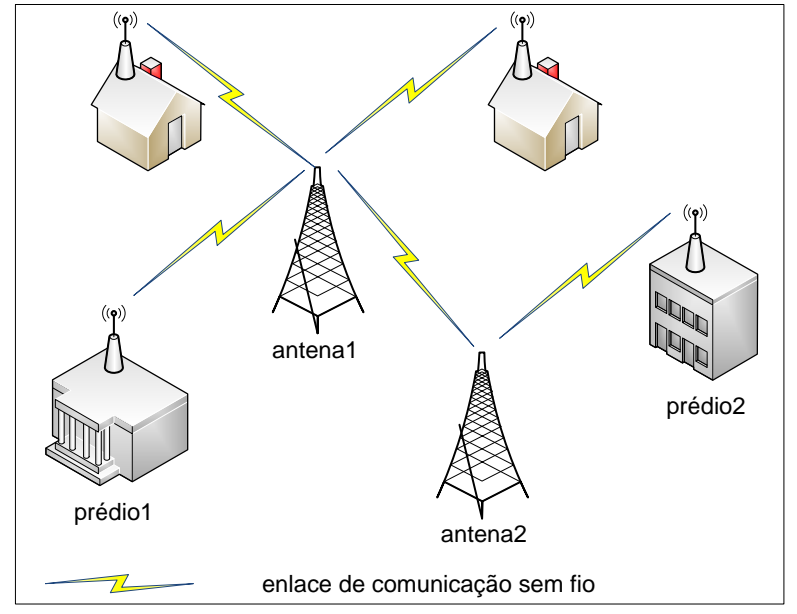

Figura 1. Rede em malha sem fio.

Para o envio dos pacotes entre os roteadores é necessário utilizar um recurso de comunicação. Um recurso corresponde a uma grandeza como tempo, frequência, espaço ou potência que quando selecionado adequadamente, conduz a rede a um maior desempenho e confiabilidade (AHMED, 2013).
O recurso utilizado neste trabalho é o canal de frequência, considerando o padrão IEEE 802.11b (Wi-Fi). O objetivo é alocar o canal de modo que pares de estações (transmissor/receptor) utilizem canais diferentes, permitindo que ocorram comunicações simultâneas na rede.

$\mathrm{Na}$ seção 2 são abordadas as características dos canais de frequência. $\mathrm{Na}$ seção 3 são apresentados alguns trabalhos relacionados. Na seção 4 é abordado o modelo rede. Na seção 5 é apresentado o protocolo proposto e na seção 6 o cenário, a simulação e discussão. Por fim, na seção 7 são apresentadas as conclusões do trabalho.

\section{CANAIS DE FREQUENCIA}

Um canal é um caminho físico utilizado por um transmissor para enviar uma informação ao receptor (HAYKIN, 2008).

Para que seja possível a transmissão e recepção do sinal é necessário que ambos, transmissor e receptor, estejam sintonizados no mesmo canal de frequência. No entanto, caso uma terceira estação decida transmitir simultaneamente no mesmo canal, ocorrerão colisões entre os pacotes das estações transmissoras (HAYKIN, 2008).

No caso da ocorrência de colisões, as informações serão corrompidas, sendo necessário a retransmissão dos dados, o que diminui o desempenho da rede. Para se diminuir as colisões é necessário controlar o 
acesso das estações ao canal ou permitir que outros pares de estações transmissor/receptor, utilizem outro canal de frequência (ZHANG, 2007).

A concessão do uso do canal de frequência pode ser realizada de duas formas: licenciada ou não licenciada (TRAGOS, 2013).

No caso da concessão licenciada é necessário obter uma autorização de uso do canal, através de uma agência reguladora de telecomunicações. No Brasil a concessão é realizada pela Agência Nacional de Telecomunicações (ANATEL) (KUNST, 2014).

No caso da concessão não licenciada não há a necessidade de autorização para o uso do canal. Exemplos de canais não licenciados são aqueles pertencentes a faixa ISM (Industrial, Scientific and Medical), que são utilizados pelos telefones sem fio, redes Wi-Fi, fornos de micro-ondas, etc (BROD, 2008).

A faixa ISM é constituída de 3 bandas de frequência: 902 a $928 \mathrm{MHz}, 2.4$ a $2.5 \mathrm{GHz}$ e 5.725 a $5.875 \mathrm{GHz}$ (BROD, 2008).
Os canais utilizados neste trabalho são os pertencentes à banda de 2.4 a 2.5 $\mathrm{GHz}$, pois são os utilizados pelas redes $\mathrm{Wi}-\mathrm{Fi}$ no Brasil. Para acessar esta banda, as redes Wi-Fi utilizam o padrão IEEE $802.11 \mathrm{~b} / \mathrm{g}$, que permite taxas de transmissões de dados de 11 e 54 Mbps, respectivamente (GAST, 2005). Este padrão disponibiliza 14 canais de frequência, conforme ilustra a Figura 2. Cada canal possui uma largura de banda de 22 $\mathrm{MHz}$ e o número do canal representa a frequência central da banda.

Como se pode observar na Figura 2, a distância entre canais centrais vizinhos é de 5 $\mathrm{MHz}$. Como cada canal possui uma largura de banda de $22 \mathrm{MHz}$ ocorre a sobreposição de bandas entre canais que são vizinhos, causando interferência entre esses canais (conhecida como interferência do canal adjacente) (DUSSAUX, 2010).

Desta forma, os canais 2, 3, 4 e 5 são interferentes com o canal 1 . Os canais 1,6 e 11 não são interferentes entre si, devido a sua distância no espectro, podendo ser utilizados simultaneamente na comunicação de dados.

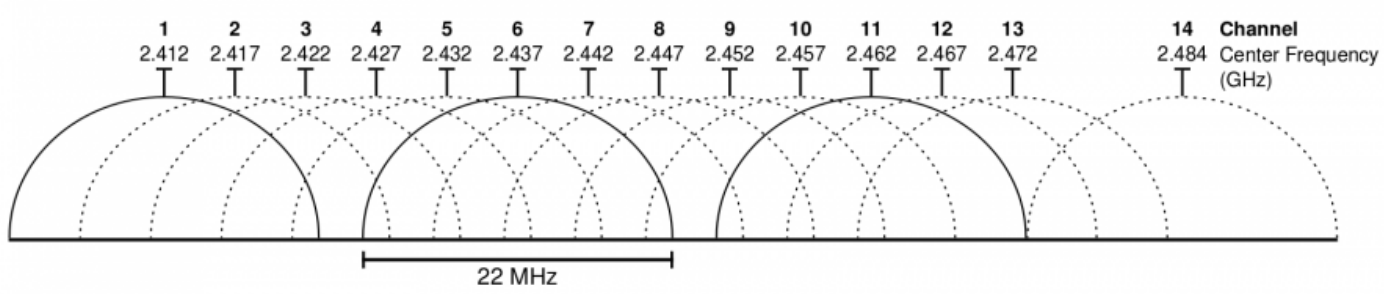

Figura 2. Canais do padrão IEEE 802.11b/g.

Fonte: (Brod, 2008). 


\section{TRABALHOS RELACIONADOS}

Vários autores abordam a utilização de parâmetros que representam recursos em redes sem fio compartilhadas.

Rondeau (2009) propõe a otimização dos recursos da rede utilizando algoritmos heurísticos. Seu trabalho busca otimizar a taxa de erros de bits, largura de banda, eficiência espectral, interferência, relação sinal/ruído, potência e vazão através de uma função multiobjetivo. Todos esses parâmetros são associados simultaneamente na função multiobjetivo e a combinação de parâmetros que resulta no melhor valor corresponde à solução do problema. Como o algoritmo utiliza heurística, a solução encontrada é muitas vezes sub-ótima, porém encontrada com menor tempo de execução computacional.

Em Khalife (2008) é apresentada duas técnicas para a troca de informações de canais.

A primeira utiliza uma janela de sincronização que consiste em usar um slot (intervalo) de tempo fixo antes de cada transmissão. Neste caso, os roteadores devem ser sincronizados no mesmo canal para a disseminação das mensagens de controle. As mensagens de controle são utilizadas para o envio de uma requisição de comutação de canal para o próximo roteador. Isto é necessário, pois ambos os roteadores necessitam estar operando no mesmo canal de frequência antes do envio da mensagem de dados.

A segunda técnica utiliza um canal específico de baixa frequência (que suporta grandes distâncias e baixas taxas de transmissões) para a troca de informações de controle. Este canal pode ser monitorado constantemente por todos os roteadores da rede.

Devido a técnica de slot de tempo fixo apresentar grande complexidade de sincronização entre os roteadores da rede, neste trabalho serão utilizados dois canais, um para a troca de mensagens de controle e o outro para o tráfego de dados. No canal de controle será utilizado um mecanismo RTS/CTS (GAST, 2005), para a reserva de recursos e controle de acesso ao meio.

Em Bennai (2010), os autores tratam a alocação de canais considerando que os roteadores são estáticos e realizam o monitoramento de todos os canais. Com o resultado do monitoramento, é calculada a taxa de utilização de cada canal que é enviada a uma estação de gerenciamento central. A estação de gerenciamento utiliza esses dados para realizar a alocação de canais com equidade entre todos os roteadores.

Em Wu (2013) os autores apresentam 3 algoritmos para a alocação de recursos.

O primeiro é baseado nas informações locais dos nós, sendo 
selecionado um canal randomicamente para o nó de origem e um canal para o nó de destino. Neste algoritmo não há nenhuma coordenação entre os nós do enlace, sendo que a probabilidade de selecionar o mesmo canal para os dois nós é pequena, resultando em baixa eficiência. Desta forma, se forem selecionados dois canais diferentes para o nó de origem e destino, não ocorrerá a transferência de dados.

No segundo algoritmo ocorre uma coordenação entre os nós e é utilizado um canal de controle para a troca de informações sobre quais canais são comuns aos dois nós.

No terceiro algoritmo a rede é representada como uma árvore de 2 níveis, formando um conjunto de estrelas. O nó com maior identificador (ID) é responsável por gerenciar os demais nós na estrela. Desta forma, cada enlace é gerenciado pelo nó que possui o mais alto ID. O algoritmo calcula a probabilidade de uma interferência acontecer e a partir desta probabilidade extrai um peso do enlace relacionado ao canal. O algoritmo procura pela melhor combinação entre enlaces e canais.

O algoritmo proposto possui semelhanças com o segundo algoritmo uma vez que ocorre a coordenação entre os nós permitindo que tanto o transmissor quanto $o$ receptor utilizem um canal comum aos dois.

\section{MODELO DE REDE}

O modelo de rede utilizado neste trabalho corresponde a uma rede em malha sem fio, onde cada roteador é representado por um nó e os enlaces de comunicação são representados por arestas em um modelo de grafo de rede. Cada nó no grafo possui duas interfaces.

A estratégia do uso de duas interfaces permite que todos os nós da rede troquem informações de controle através de um canal comum. Além disso, evita que o tráfego gerado pelas operações de controle (interface de controle) da rede interfira no tráfego de dados (interface de dados) e viceversa.

No modelo de rede, a primeira interface é a responsável pelas operações de controle. As operações de controle incluem a distribuição de mensagens que informam os canais disponíveis, mensagens para solicitar a comutação de canal a um nó vizinho e mensagens de roteamento. A segunda interface é responsável somente pelo envio de dados até o nó vizinho.

$\mathrm{Na}$ interface de controle e de dados, considerou-se o tamanho de pacote padrão do simulador NS-3 (1000 bytes), uma vez que o objetivo é manter as interfaces ocupadas para verificar a interferência entre os enlaces.

A Figura 3 ilustra a representação do modelo de rede. 


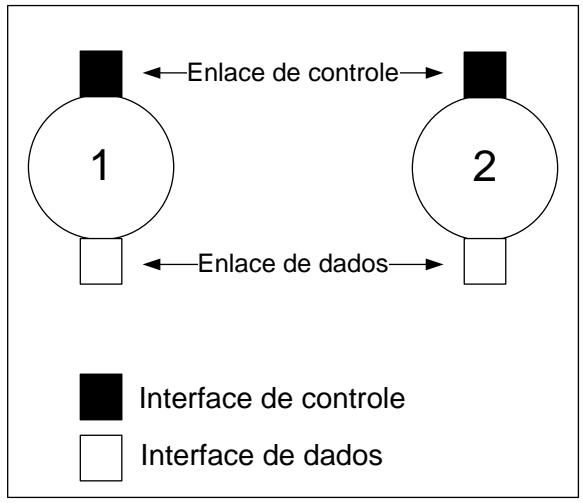

Figura 3. Modelo de rede.

As interferências nos enlaces ocorrem se dois enlaces são vizinhos e utilizam o mesmo canal de comunicação (SUBRAMANIAN, 2007).

A Figura 4 ilustra dois enlaces interferentes em uma rede constituída de 4 nós.

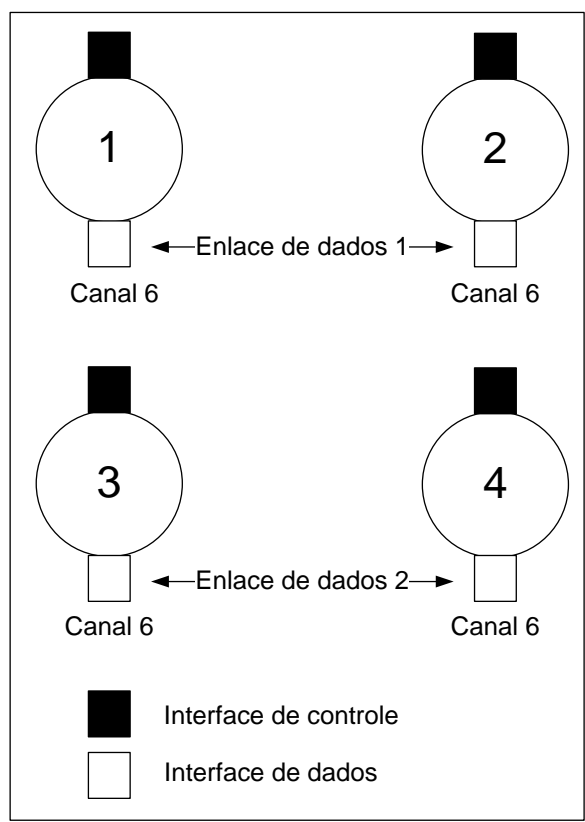

Figura 4. Interferência entre enlaces.

Como se pode observar na Figura 4, os enlaces de dados 1 e 2 são interferentes, pois utilizam o mesmo canal de frequência (canal 6). Neste caso, ocorrerão colisões e será necessária a retransmissão dos pacotes, diminuindo a vazão da rede.

\section{PROTOCOLO PROPOSTO}

O protocolo proposto utiliza mensagens de hello para cada nó da rede anunciar periodicamente os seus vizinhos e os seus canais disponíveis. Neste trabalho, considerou-se uma periodicidade de 2 segundos (o mesmo utilizado pelo protocolo de roteamento).

Ao receber uma mensagem de hello, um nó retira a lista de canais disponíveis da mensagem e realiza a intersecção desta lista com a sua lista de canais locais. O resultado da intersecção corresponde a uma lista de canais comuns que é utilizada para a alocação de canais.

A Figura 5 ilustra um exemplo do envio das mensagens de hello e da obtenção da lista de canais comuns.

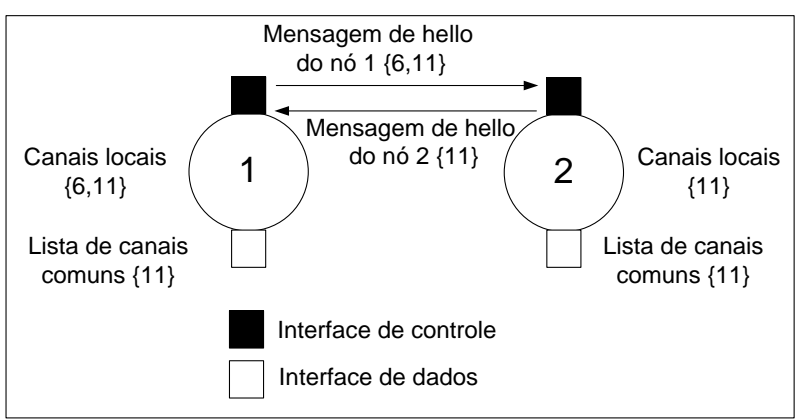

Figura 5. Envio da mensagem de hello e lista de canais comuns. 
Na Figura 5, o nó 1 possui a lista de canais locais $\{6,11\}$. Periodicamente a lista é enviada aos nós vizinhos através das mensagens de hello. O nó vizinho 2 recebe a mensagem e realiza a intersecção da lista de canais da mensagem de hello $\{6,11\}$ com a sua lista de canais locais $\{11\}$. A lista de canais resultante corresponde a lista de canais comuns $\{11\}$ que é utilizada pelo nó para alocar o canal ao enlace.

O nó 1 ao receber uma mensagem de hello do nó 2, realiza o mesmo processo, calculando a intersecção da lista de canais disponíveis recebida pela mensagem de hello $\{11\}$ com a sua lista de canais locais $\{6,11\}$.

Para controlar o acesso ao canal são utilizadas mensagens RTS/CTS (Request-toSend/(Clear-to-Send). Quando um nó deseja enviar um pacote de dados ao seu destino, ele envia uma mensagem RTS/CTS como ilustra a Figura 6.

A mensagem RTS contém o número do canal no qual o nó deseja realizar a transmissão. O nó vizinho ao receber a mensagem, obtém o número do canal e verifica se ele consta na sua lista de canais comuns. Caso conste, ele comuta para o número do canal e retorna uma mensagem CTS, confirmando ao nó de origem que ele pode transmitir naquele canal.

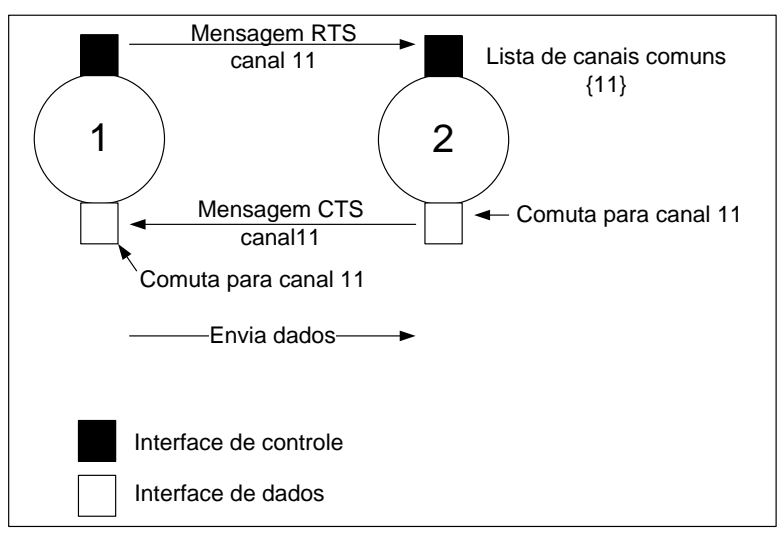

Figura 6. Troca de mensagens RTS/CTS.

No exemplo da Figura 6, o nó 1 envia uma mensagem RTS/CTS sinalizando que deseja transmitir no canal 11 . O nó 2 ao receber a mensagem, verifica se o canal 11 está em sua lista de canais comuns. Como o canal 11 consta na lista, o nó 2 comuta para o canal 11 e retorna uma mensagem de CTS informando ao nó 1 que ele pode transmitir no canal 11 . O nó 1 ao receber a mensagem de CTS, comuta para o canal 11 e envia o pacote de dados. O protocolo proposto pode ser representado por um diagrama de estados como ilustra a Figura 7.

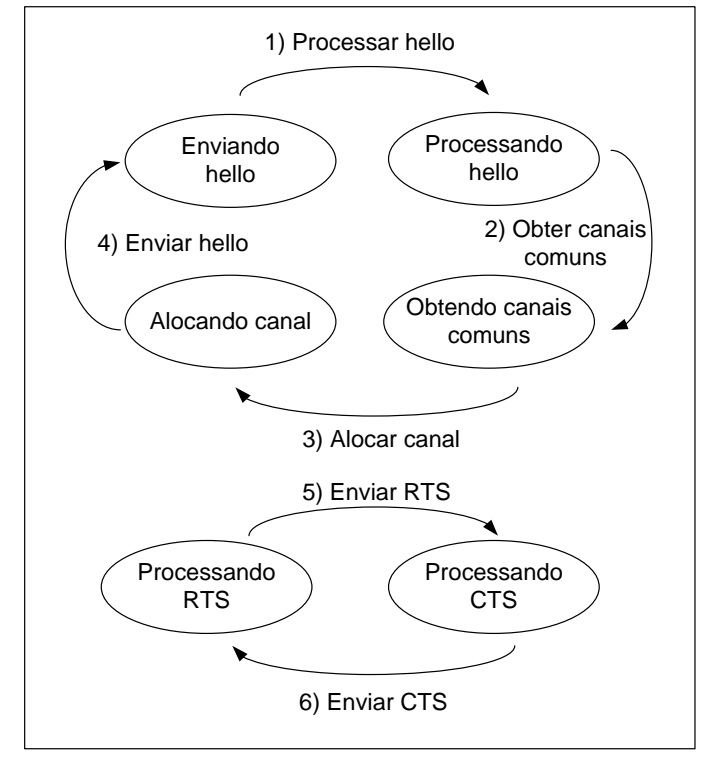

Figura 7. Diagrama de estados. 
Cada nó na rede pode estar em 4 estados possíveis em relação a alocação de canal: enviando hello, processando hello, obtendo canais comuns ou alocando canais.

No estado enviando hello, o nó envia a mensagem contendo a lista de canais disponíveis.

No estado processando hello, o nó recebe a mensagem de hello e retira a lista de canais disponíveis do nó vizinho.

No estado obtendo canais comuns, o nó realiza a intersecção entre a lista de canais da mensagem de hello com a sua lista de canais locais.

Por fim, no estado alocando canal, um canal da lista de canais comuns é atribuído randomicamente ao nó para iniciar o processo de transmissão de um pacote de dados.

Em relação ao controle de acesso e sincronização de canais, o nó pode estar nos estados processando RTS e processando CTS, que são ativados somente após a alocação dos canais e quando o nó deseja enviar um pacote de dados.

\section{CENÁRIO, SIMULAÇÃO E DISCUSSÃO}

Para a realização dos experimentos é utilizado o simulador de redes NS-3, utilizando a linguagem de programação $\mathrm{C}++$. No simulador é definido um cenário de redes, em que os nós estão dispostos em uma topologia em malha.
A topologia é constituída de 16 nós estáticos, localizados a uma distância de 500 $\mathrm{m}$ um do outro. A área de cobertura para a distância de $500 \mathrm{~m}$ é obtida utilizando antenas com maiores ganhos de transmissão, ao contrário das redes sem fio convencionais que utilizam antenas de menor potência, limitando o alcance da rede.

A interface de controle está configurada no canal 1 de forma que os nós da rede possam trocar as mensagens de hello e RTS/CTS e está configurada no endereço de rede 10.1.1.0/24.

A interface de dados comuta o canal de acordo com o canal alocado e está configurada no endereço de rede 10.1.2.0/24

A Figura 8 ilustra a topologia utilizada no cenário de simulação.

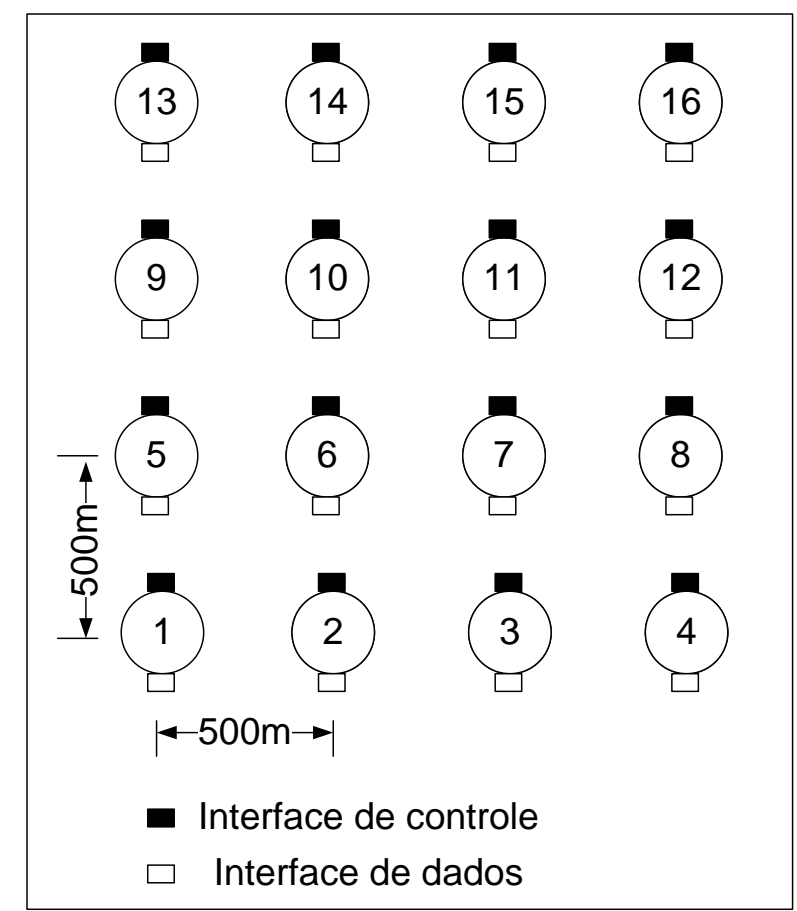

Figura 8. Cenário de simulação. 
No cenário ilustrado na Figura 8, cada nó está separado a uma distância de 500 m, com uma potência de transmissão que permite um raio de cobertura de sinal de 656 m. Desta forma, cada nó reconhece seu vizinho direto (a 1 salto). Caso o destino esteja a mais de 1 salto de distância, o pacote será reencaminhado pelo nó intermediário.

A técnica de modulação empregada é a DSSS com o modelo de atraso de propagação ConstantSpeedPropagationDelay Model e o modelo de perda de propagação FriisPropagationLossModel [STOFFERS, 2012].

Esses modelos foram escolhidos, pois são os modelos que são utilizados nos exemplos padrões do simulador. No entanto, poderia ser utilizado qualquer outro modelo, desde que garanta um raio de cobertura de sinal maior que 500 e menor $750 \mathrm{~m}$ para que as mensagens de hello não alcancem diretamente um vizinho a 2 saltos de distância.

Na simulação, cada pacote possui um tamanho de 1000 bytes. Foram gerados 3 fluxos paralelos e simultâneos de dados. Cada fluxo gera um tráfego de 1000 pacotes , de modo que, caso dois enlaces vizinhos possuam o mesmo canal alocado, ocorrerá interferência entre esses enlaces, diminuindo a vazão da rede.

No cenário considera-se o pior caso, uma vez que, vários enlaces vizinhos estão ativos simultaneamente e a atribuição de canal ocorre de forma aleatória.

Os fluxos foram gerados por 30 segundos (do instante $12 \mathrm{~s}$ ao instante $42 \mathrm{~s}$ ).

A Tabela 1 ilustra os fluxos gerados, os nós de origem e de destino e o número de pacotes de cada fluxo.

Tabela 1. Fluxos gerados.

\begin{tabular}{|c|c|c|c|}
\hline Fluxos & $\begin{array}{c}\text { Nó de } \\
\text { origem }\end{array}$ & $\begin{array}{c}\text { Nó de } \\
\text { destino }\end{array}$ & $\begin{array}{c}\text { Quantidade } \\
\text { de pacotes }\end{array}$ \\
\hline Fluxo 1 & 1 & 4 & 1000 \\
\hline Fluxo 2 & 5 & 8 & 1000 \\
\hline Fluxo 3 & 9 & 12 & 1000 \\
\hline
\end{tabular}

Os fluxos de dados têm início no instante 12 segundos para que ocorra a convergência do algoritmo de alocação de canais e a convergência do algoritmo de roteamento.

A Tabela 2 ilustra um exemplo de tabela de alocação de canais resultante da topologia simulada, considerado 2 canais disponíveis (6 ou 11). Na Tabela 2, cada par de nós (enlace) corresponde a uma aresta no grafo, no qual foi alocado um canal.

A tabela de alocação de canais sofrerá uma nova mudança somente em duas situações, ou quando ocorrer uma mudança de topologia na rede, ou quando ocorrer uma mudança na disponibilidade de canais. 
Tabela 2. Canais alocados aos pares de nós.

\begin{tabular}{|c|c|}
\hline Par de nós (enlace) & Canal alocado \\
\hline $1-2$ & 11 \\
\hline $1-5$ & 6 \\
\hline $2-3$ & 6 \\
\hline $2-6$ & 11 \\
\hline $3-4$ & 6 \\
\hline $3-7$ & 11 \\
\hline $4-8$ & 6 \\
\hline $5-6$ & 11 \\
\hline $5-9$ & 6 \\
\hline $6-7$ & 11 \\
\hline $6-10$ & 11 \\
\hline $7-8$ & 11 \\
\hline $7-11$ & 11 \\
\hline $8-12$ & 6 \\
\hline $9-10$ & 11 \\
\hline $9-13$ & 11 \\
\hline $10-11$ & 11 \\
\hline $10-14$ & 11 \\
\hline $11-12$ & 11 \\
\hline $11-15$ & 11 \\
\hline $12-16$ & 11 \\
\hline $13-14$ & 11 \\
\hline $14-15$ & 6 \\
\hline $15-16$ & 11 \\
\hline
\end{tabular}

A Figura 9 ilustra a vazão resultante variando-se o número de canais disponíveis na rede.

A curva inferior representa a alocação utilizando um único canal (monocanal). A curva superior representa a alocação variando-se o número de canais (multicanal).

De acordo com o gráfico a vazão resultante da utilização de 1 ou 2 canais possuem valores bem próximos. Isto é decorrente dos fluxos simultâneos e paralelos que foram gerados de uma extremidade da malha até a outra.

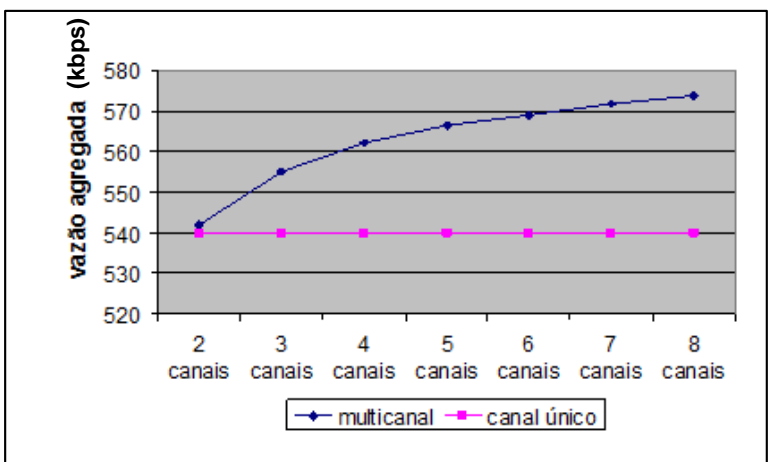

Figura 9. Cenário de simulação

Como há somente dois canais e os fluxos são simultâneos, uma aresta de um fluxo ativo acaba interferindo nas arestas de fluxos ativos vizinhos. Para exemplificar esta situação, a Figura 10, ilustra o cenário de rede com a atribuição de 2 canais e 3 fluxos gerados simultaneamente.

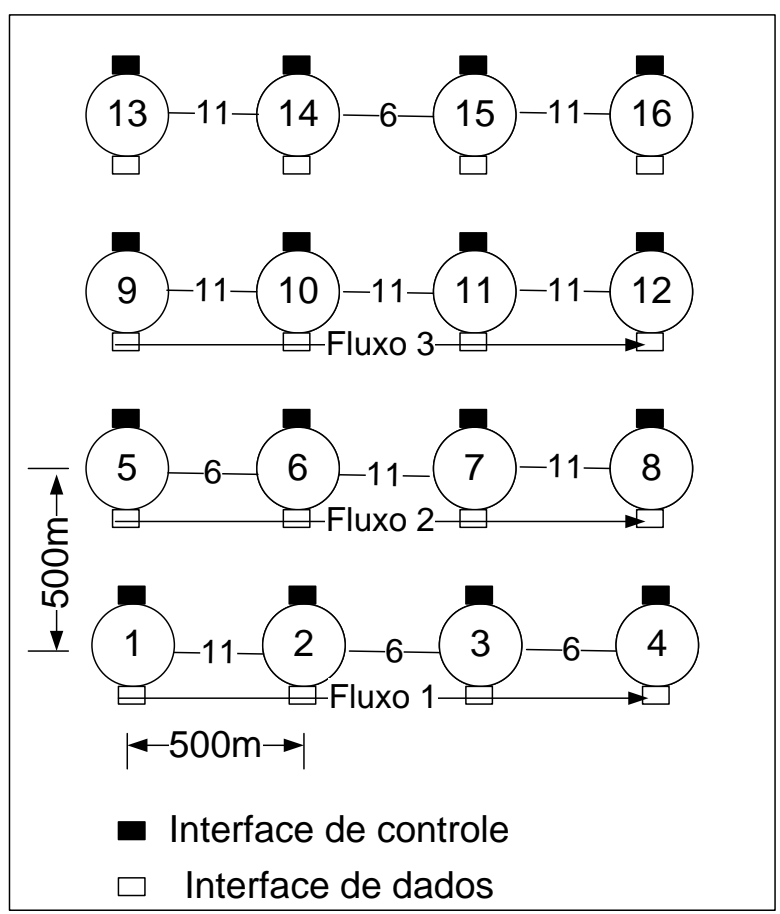

Figura 10. Cenário de simulação com fluxos de dados simultâneos.

Na Figura 10, a transmissão do nó 1 para o nó 2 interfere na transmissão do nó 6 ao nó 7. Da mesma forma, a transmissão do 
nó 2 ao nó 3 interfere na transmissão do nó 5 ao nó 6.

No entanto conforme se aumentou o número de canais disponíveis ocorreu o aumento da vazão, decorrente da melhor distribuição dos canais na rede. Para 3 canais ocorreu um aumento médio de $4 \%$ e para 4 canais o aumento médio foi de $5.5 \%$.

\section{CONCLUSÕES}

Com o trabalho, pode-se observar que a alocação de canais diferentes para os enlaces permite aumentar a vazão da rede. Mesmo considerando o pior cenário de interferência em que os fluxos são gerados de maneira paralela e simultaneamente e a atribuição de canais é realizada de forma randômica, ocorreu o ganho de vazão com o aumento do número de canais. Como trabalhos futuros, pretende-se otimizar o protocolo para cenários em que a alocação de canal prioriza os enlaces com maior tráfego de rede. Desta forma, é possível diminuir a interferência dos enlaces de menor tráfego, sobre os enlaces que conduzem, por exemplo, o tráfego para a Internet.

\section{AGRADECIMENTOS}

Os autores agradecem à Universidade Paranaense pelo apoio financeiro.

\section{REFERÊNCIAS}

AHMED, I. et al. On the fairness of resource allocation in wireless mesh networks: a survey. Journal Wireless Network, v.19, n.4,
BENNAI, M.; SYDOR, J.; RAHMAN, $M$. Automatic channel selection for cognitive radio systems in wireless environments. IEEE International Symposium on Personal, Indoor and Mobile Radio Communications, p. 1831-1835, 2010. http://dx.doi.org/10.1109/PIMRC.2010.5671 $\underline{634}$

BROD, C. et. al. Redes sem fio no mundo em desenvolvimento. Hacker Friendly, 2008.

DUSSAUX, G. et al. Tecnologias de rede em telefonia móvel. Disponível em: < http://www.gta.ufrj.br/grad/10_1/movel/ind ex.html>. Acesso em: 30 ago. 2014.

GAST, M. Wireless networks: the definitive guide. Sebastopol: O’Reilly Media Inc., 2005.

HAYKIN, S.; MOHER, M. Sistemas modernos de comunicações wireless. Bookman, 2008.

KHALIFE, H.; AHUJA, S. Joint routing and spectrum selection for multihop cognitive radio networks. Disponível em: < http://citeseerx.ist.psu.edu/viewdoc/downlo ad?doi=10.1.1.218.8773\&rep=rep1\&type=pd f >. Acesso em: 07 mar. 2013.

KUNST, R.; SEHNEM, D. Uma análise da alocação do espectro de frequências aplicada as redes de rádio cognitivo. Disponível em < http://online.unisc.br/acadnet/anais/index.p hp/salao_ensino_extensao/article/view/5033 >. Acesso em: 30 ago 2014

RONDEAU, T. W.; BOSTIAN, C. W. Artificial intelligence in wireless communications. Norwood:Artech House, 2009.

SUBRAMANIAN, A.; GUPTA, H.; DAS, S.R. Minimum-interference channel assignment in multi-radio wireless mesh networks. 
Disponível em <

http://www.cs.sunysb.edu/ hgupta/ps/chan nel.pdf >. Acesso em: 05 abr. 2013.

STOFFERS, M.; RILEY, G. Comparing the ns-3 propagation models. IEEE Modeling, Analysis and Simulation of Computer and Telecommunication Systems. p.61-67, 2012. http://dx.doi.org/10.1109/mascots.2012.17

TRAGOS, E. et al. Spectrum assignment in cognitive radio networks: a comprehensive survey. IEEE Communications Surveys and Tutorials, v.15, n.3, p.1108-1135, 2013. http://dx.doi.org/10.1109/SURV.2012.12111 $\underline{2.00047}$

WU, J.; DAI, Y.; ZHAO, Y. Effective channel assignments in cognitive radio networks. ACM Journal Computer Communications, v. 36, n. 4, p.411-420, 2013. http://dx.doi.org/10.1016/i.comcom.2012.10 .008

ZHANG, Y.; LUO, J.; HU, H. Wireless mesh networking. New York:Auerbach Publications, 2007. 